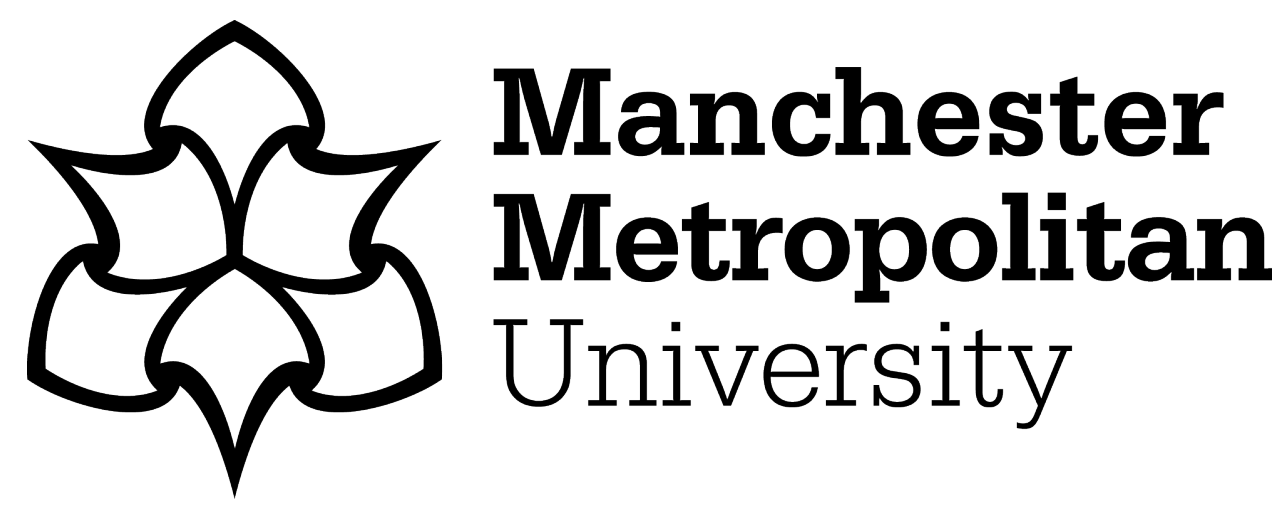

Brearley, FQ and Rod Cullen, W (2012) Providing students with formative audio feedback. Bioscience Education, 20 (1). pp. 22-36.

Downloaded from: https://e-space.mmu.ac.uk/624007/

Version: Published Version

Publisher: Taylor \& Francis (formerly Higher Education Academy)

DOI: https://doi.org/10.11120/beej.2012.20000022

Please cite the published version 


\title{
Providing Students with Formative Audio Feedback
}

\author{
Francis Q. Brearley ${ }^{1} \&$ W. Rod Cullen ${ }^{2}$ \\ ${ }^{1}$ School of Science and the Environment, Manchester Metropolitan University, UK \\ ${ }^{2}$ Centre for Learning and Teaching, Manchester Metropolitan University, UK
}

Corresponding author:

Dr W. Rod Cullen, Learning Innovations, LRT, Manchester Metropolitan University, All Saints, Manchester M1 6BG, UK

Email: r.cullen@mmu.ac.uk, Phone: 01612473356

\section{Abstract}

The provision of timely and constructive feedback is increasingly challenging for busy academics. Ensuring effective student engagement with feedback is equally difficult. Increasingly, studies have explored provision of audio recorded feedback to enhance effectiveness and engagement with feedback. Few, if any, of these focus on purely formative audio feedback on draft submissions of written assignments. This study encouraged a cohort of 40 students to submit drafts of written assignments, two weeks before formal submission, in order to receive audio recorded feedback.

Nearly half the cohort either did not submit drafts or submitted only brief outlines. The level of draft completeness impacted on the characteristics of the lecturer's feedback. While students receiving audio feedback gained significantly higher marks for finished work, this cannot be directly attributed to receipt/use of feedback as analysis suggests generally more able students are more likely to submit more complete drafts, which leads us to ask the question, are we simply helping better students to perform even better? Audio feedback was reported as clear, engaging and helpful; however, timing of feedback (before formal submission) may be of greater importance in terms of impact on attainment than the audio format. We suggest a model that focuses efforts on formative feedback (in advance of formal submission) and selective provision of summative feedback (targeted feed forward).

Keywords: attainment, audio recordings, feedback, formative assessment

\section{Introduction}

Increasingly, academics are faced with larger class sizes, less face-to-face contact with students and additional demands on their time in terms of university administration and research. Many commentators argue that the provision of timely, relevant and constructive feedback is the most important factor for enhancing student learning (Gibbs \& Simpson 2004, Biggs \& Tang 2007, Race 2010). However, resource constraints make assessing student work and providing essential feedback, of sufficient quantity and quality, within an appropriate timescale ever more challenging (Gibbs \& Simpson 2004). The provision of 
feedback has also been shown to be an area where students are less satisfied with their university education (Lipsett 2007, Holmes \& Papageorgiou 2009) receiving one of the lower scores in the National Student Survey (Fielding et al. 2010). Producing feedback is only part of the challenge; equally difficult is ensuring that students engage effectively with the feedback they receive (Cullen 2011, Orsmond \& Merry 2011) and academics frequently report frustration that students fail to act on feedback or even to collect it at all (Bloxham \& Boyd 2007, Jollands et al. 2009).

Summative and formative assessment are generally regarded as serving clearly distinct purposes (Biggs \& Tang 2007). Summative assessment relates to assessment of learning, expressed as marks or grades while formative assessment relates to assessment for learning, linked explicitly to the provision of feedback. Black \& Wiliam (1998a) highlight the tensions which can occur, for both students and teachers, when assessments serve both formative and summative purposes, where if an appropriate balance is not achieved formative work will always be threatened due to the dominance of summative requirements. In practice, a considerable amount of assessment in higher education (HE) seems to fall between these two categories and attempts to serve both formative and summative purposes. For example, students may receive both a mark and written feedback on an essay assignment. The mark contributes to the students' overall summative grade for a unit or module and the feedback is intended as formative provision to enable the students to reflect and learn from the experience. This probably describes the majority of university students' experience of receiving feedback. Perhaps the most important aspect of this example is that the student receives feedback on an assignment at a time when they have already received a mark. Consequently, they are unable to apply any learning gained from engaging with the feedback to the assessment task to which it relates. Feedback provided at this stage can only be of use to students in future assignments. The notion of feedback as 'feed forward' (Race 2010), providing guidance on how to make use of feedback becomes important in this respect. However, Orsmond \& Merry (2011) report that feedback provided by a sample of bioscience lecturers focused on performance on the assignment being assessed (explaining misunderstanding relating to the current work) and no lecturers provided any suggestions on approaches to future assignments. In addition, other authors have reported that students often struggle to transfer learning from one unit to another (Orsmond \& Merry 2011). Biggs \& Tang (2007) do not regard the assessment practice described earlier as formative as the feedback is provided when the unit is effectively finished and students rarely pay attention to comments provided at the end of a course. Jollands et al. (2009) conclude that lecturers identified, by students, as exemplary in terms of feedback provision believed that students are much more likely to collect, read and act on feedback if it is on truly formative assessments, such as comments on essay drafts rather than on feedback provided on summative assessments (as described earlier). The terms formative feedback (feedback provided on work in progress) and summative feedback (provide on work which has already received a summative mark) (borrowed from Phil Race, personal communication) may be useful terms to distinguish between feedback provided at different timings with respect to formal assessment.

Most feedback is provided in written format (as annotations to student work and/or on written forms returned along with the mark for the work) or verbally in face-to-face teaching situations (e.g. tutorials, seminars or lectures). Glover \& Brown (2006) comment that, in terms of written feedback, students receive plenty of it, but that it is often misunderstood in relation to assessment criteria. Orsmond et al. (2005) found that a majority of students preferred verbal feedback from lecturers as it enabled questioning and discussion. Interest in the provision of verbal feedback in the form of digital audio files (commonly referred to as audio feedback) has increased in parallel with the availability of cheap, easy to use recording devices and computer software (France \& Wheeler 2007, Rotherham 2007, 
Middleton 2011). Merry \& Orsmond report that students perceived and implemented audio feedback in different and more meaningful ways than written feedback, and McCullagh (2011) noted that audio feedback can play an important role in accommodating learner preferences and different learning styles. Rotherham (2007) has reported that audio feedback can be produced quickly and easily using simple MP3 recorders in a similar time frame to equivalent written feedback and Cullen (2011) concluded that audio feedback was more time efficient than equivalent amounts of written or video screen capture feedback for similar assignments.

Whilst there are an increasing number of studies that address the use of audio feedback, few, if any, have addressed the use of audio recordings strictly as formative feedback, i.e. at the stage where students are able to respond to feedback while working on a specific assignment and potentially improve their attainment. Although the overall assessment strategy includes the provision of summative feedback, this paper primarily examines the use of audio recordings to provide formative feedback for a written assignment. The study specifically examines:

- Student uptake and engagement with formative feedback delivered via audio files.

- The characteristics of the audio feedback produced by the lecturer.

- Student perceptions of formative audio feedback.

- The impact of formative audio feedback on final submissions and attainment.

\section{Methods}

The study adopted an action research approach to develop a better understanding of practice (Carr \& Kemmis 1986) in relation to provision of formative audio feedback. Briefly, we planned and implemented an assessment strategy to incorporate the provision of formative audio feedback, monitored and collected relevant data for analysis and this forms the basis of reflection in our discussion.

\section{The assessment strategy}

The study was undertaken within a 20 credit, third-year (level six) undergraduate unit, 'Tropical Land Use and Conservation', taught in the School of Science and the Environment at Manchester Metropolitan University (2010/2011 cohort). The unit had a cohort of 40 students who were invited to participate in the study.

In brief, students were set a written assignment mid-way through the autumn term and encouraged to submit a draft on which audio feedback was provided two weeks before the final submission deadline near the end of term. A full overview of the assessment strategy, including the formative and summative feedback elements, employed in the study is provided in Table 1.

\section{Production of the audio feedback}

The audio feedback was produced in five stages:

1. Each submission received via e-mail was initially printed off.

2. Work was read and annotated by the lecturer with rough hand written comments. These were intended for the lecturer's use only to highlight key feedback issues to be included in the audio feedback. The annotations were focused on structure, detail of content, misunderstandings, grammar/spelling and referencing but addressed more specific issues as they arose in individual drafts. 
Table 1 Overview of the assessment strategy used to provide student formative feedback via audio files.

\begin{tabular}{ll}
\hline Date & Activity \\
\hline 25 October 2010 & Assignment set and distributed with a standard institutional assignment \\
& cover sheet including a grading scheme. \\
& Assignment Title: 'Review the effects of plantations on a named group of \\
& organisms in the tropics' \\
& Assignment Format: 2000 word written report \\
& Students were informed of the project via a letter distributed with the \\
& assignment cover sheet explaining the audio feedback project. This \\
& emphasised that audio feedback would be provided on a formative (draft) \\
& assignment submitted to the tutor via e-mail by 25 November 2010. \\
& The purpose of the formative feedback was explained to the students \\
& and the submission of the draft was greatly encouraged but not a specific \\
& requirement. \\
& Essay writing workshop \\
22 November 2010 & All students reminded of formative (draft) submission deadline via e-mail \\
24 November 2010 & Draft submission deadline for students \\
25 November 2010 & Formative audio feedback produced \\
$25-30$ November 2010 & Drafts reviewed, annotated, audio feedback recorded and distributed to \\
& students \\
6 December 2010 & Formal submission of completed assignment for summative assessment \\
& Summative audio feedback produced \\
& Formal submission marked, audio feedback recorded and released to \\
& students \\
\hline
\end{tabular}

3. Audio feedback was recorded onto a handheld digital voice recorder (Olympus WS-210S) with an external lapel microphone. By default, files were saved on the device in WMA (Windows Media Audio) format with no attempt made at file compression.

4. The voice recorder was connected via a USB cable to the lecturer's computer. The file(s) were checked (to ensure the recording had been made), and then copied across to the hard drive using a consistent file naming convention 'SurnameForenameFormative. wma' or 'SurnameForenameSummative.wma' (depending on the feedback being produced).

5. Each file was e-mailed to the student by replying to their original submission e-mail including a short friendly message along the lines of ' $\mathrm{Hi}$ Student A, Please find your feedback attached - I hope you find it useful. Lecturer B'.

\section{Data collection}

The formative submissions were classified in relation to their level of completeness.

(a) Complete - judged to be near complete pieces of work in terms of word length, structure and content.

(b) Work in progress - judged as either partially complete (shorter than the specified word length) or a semi-structured presentation of main topics to be included.

(c) Outline - judged to be no more than an outline plan of the work to be undertaken, very short in terms of the word count with limited content and minimal discussion. 
The following information was collected by the lecturer during the production of the formative and summative audio feedback.

1. Time and date of draft submission receipt.

2. Time taken to:

(a) open, print, read and mark each assignment,

(b) record the feedback,

(c) copy, check, rename and send each file.

Each instance of feedback was subsequently analysed with respect to the types of feedback comments contained using the following criteria.

(a) re-assurance/positive reinforcement (pointing out what has been done well),

(b) content (suggestions for content to be added/removed),

(c) improvements in structure (suggestions for re-organising sections/paragraphs in the work),

(d) provision of more evidence (suggestions of additional/better quality references),

(e) grammar/spelling/referencing errors,

(f) factual errors,

(g) reiterating what was expected from the assignment.

\section{Questionnaire survey}

Seventeen students who attended the final session for the unit on 13 December 2010 were invited to complete a paper-based questionnaire survey relating to their experience of the audio feedback provided as part of the unit. No responses were received from students who had not submitted a draft.

\section{Statistical analysis}

The final performance of students who received audio feedback and those that did not was compared using a two-sample $t$-test, comparisons between the draft essays in terms of their characteristics were made with a one-way analysis of variance (ANOVA) (data was log-transformed as required); all analyses were performed using Minitab 15.1.

\section{Results and Discussion}

\section{Student uptake and engagement with formative feedback delivered via audio files}

Twenty-five students (63\% of the cohort) chose to submit drafts. The majority of the submissions $(60 \%)$ were classified as work in progress, about a quarter of submissions were merely brief outlines and the smallest proportion (16\%) constituted complete drafts (Table 2). One interpretation of this is that only $48 \%$ (19 out of 40 ) of the cohort valued the opportunity to receive formative feedback on the assignment enough to submit work that could be classed as at least a work in progress. This is similar to McClean (2008) who reported a $50 \%$ uptake of formative feedback at the University of Ulster. The timings of draft submissions were clustered around the deadline with most coming in on the deadline day, within a few hours of the deadline. It is worth noting that $16 \%$ of the drafts did arrive four to nine days before the assignment deadline (Figure 1). Interestingly, drafts that were classified as complete were submitted significantly earlier than less complete work and, as 
Table 2 Characteristics of student submissions and tutor feedback on draft essays submitted and provided with formative feedback via audio files.

\begin{tabular}{|c|c|c|c|c|}
\hline Type of draft & Complete & Work in progress & Outline & Comment \\
\hline $\mathrm{N}$ & $\begin{array}{c}4 \\
(16 \%)\end{array}$ & $\begin{array}{c}15 \\
(60 \%)\end{array}$ & $\begin{array}{c}6 \\
(24 \%)\end{array}$ & $\begin{array}{l}\text { The majority of } \\
\text { submissions were } \\
\text { works in progress. }\end{array}$ \\
\hline Words & $\begin{array}{c}2489 \pm 368 \\
a\end{array}$ & $\begin{array}{c}1342 \pm 87 \\
b\end{array}$ & $\begin{array}{c}427 \pm 73 \\
c\end{array}$ & $\begin{array}{l}\text { Level of completion } \\
\text { was reflected in word } \\
\text { count for submissions. }\end{array}$ \\
\hline $\begin{array}{l}\text { Time of submission (days } \\
\text { before deadline) }\end{array}$ & $\begin{array}{c}5.0 \pm 1.0 \\
a\end{array}$ & $\begin{array}{c}0.13 \pm 0.24 \\
b\end{array}$ & $\begin{array}{c}-0.50 \pm 0.62 \\
b\end{array}$ & $\begin{array}{l}\text { Submissions classified } \\
\text { as complete were } \\
\text { submitted significantly } \\
\text { earlier than less } \\
\text { complete work. }\end{array}$ \\
\hline $\begin{array}{l}\text { Length of feedback } \\
\text { (seconds) }\end{array}$ & $\begin{array}{c}316 \pm 33 \\
a\end{array}$ & $\begin{array}{c}198 \pm 11 \\
b\end{array}$ & $\begin{array}{c}105 \pm 19 \\
c\end{array}$ & $\begin{array}{l}\text { Significantly more } \\
\text { feedback was provided } \\
\text { on more complete } \\
\text { work. }\end{array}$ \\
\hline $\begin{array}{l}\text { Focus of the feedback } \\
\text { Key } \\
\begin{array}{|l}\text { Spellings/References } \\
\text { Positive comments } \\
\text { Content } \\
\text { Structure } \\
\text { Errors } \\
\text { Evidence } \\
\text { Reinteration }\end{array}\end{array}$ & & & & $\begin{array}{l}\text { Feedback on outline } \\
\text { drafts focused on } \\
\text { reiteration of the task } \\
\text { and suggestions about } \\
\text { evidence that might be } \\
\text { included. } \\
\text { For more complete } \\
\text { drafts the relative } \\
\text { focus was on fine } \\
\text { tuning of the work such } \\
\text { as grammar, spelling } \\
\text { and references and } \\
\text { encouraging, positive } \\
\text { comments. }\end{array}$ \\
\hline Final mark awarded (\%) & $\begin{array}{c}69.8 \pm 2.8 \\
a\end{array}$ & $\begin{array}{c}61.6 \pm 1.8 \\
a\end{array}$ & $\begin{array}{c}51.8 \pm 2.8 \\
b\end{array}$ & $\begin{array}{l}\text { Students who made } \\
\text { formative submissions } \\
\text { that were classed as } \\
\text { 'complete' or 'work in } \\
\text { progress' attained } \\
\text { significantly higher final } \\
\text { marks for the assignment. }\end{array}$ \\
\hline $\begin{array}{l}\text { Overall mark for second } \\
\text { year }(\%)^{*}\end{array}$ & $\begin{array}{c}66.6 \pm 6.35 \\
a\end{array}$ & $\begin{array}{c}61.3 \pm 7.83 \\
a\end{array}$ & $\begin{array}{c}46.2 \pm 10.20 \\
b\end{array}$ & $\begin{array}{l}\text { Students who made } \\
\text { formative submissions } \\
\text { that were classed as } \\
\text { 'complete' or 'draft' } \\
\text { attained significantly } \\
\text { higher final mark } \\
\text { overall for level five. }\end{array}$ \\
\hline
\end{tabular}

Note: All values mean \pm standard error. Significant differences between draft types determined by Tukey's test are noted by a, b, c, etc.

*Two students could not be included in this analysis as they were overseas for part of the second year.

we might expect, the word count of the submissions reflected this (Table 2). This is somewhat suggestive of some students being better organised in their work to take advantage of the opportunity to receive feedback and this is backed up with text comments from the survey from some students relating to non-submission which included:

\section{'bad time management' \\ 'couldn't get it finished in time' \\ 'not enough time'}




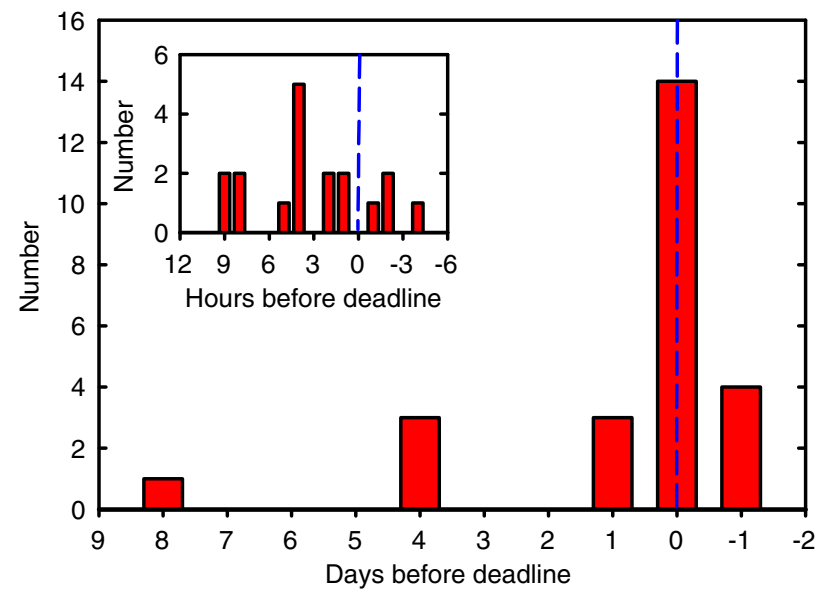

Figure 1 Histogram of time before the deadline of submission of draft essays for audio feedback. The main graph shows the number of days before the deadline whereas the inset shows the number of hours before the deadline for those submitted close to the deadline. The blue dotted line represents the hand-in deadline.

The majority of students who received feedback indicated that they had acted upon it in responses to an open text question in the survey: 'What did you change in your essay in response to the feedback?' For example:

'Structure, corrected minor mistakes'

'Lots. It needed a lot of work. Draft was hardly started'

'Restructured parts, knew what to take out, and was good to have a review of assignment before it was due.'

Furthermore, all of the students who received feedback considered that the feedback was helpful (Table 3, Q1). Some students entered into follow-up e-mail exchanges seeking clarification on aspects of the feedback. For example, one student queried feedback on the content of their assignment and asked 'would you really not advise me to discuss agroforestry in the essay?' This required the lecturer to go into greater detail on the advice provided, but demonstrates that the feedback was instrumental in the student reflecting upon and questioning the feedback, resulting in a useful dialogue with the lecturer.

One student asked the rather puzzling question 'if I don't make the changes you suggested will I lose marks?'. This question suggests that this student did not fully grasp the purpose of the feedback. They seem to be asking 'is what I have done good enough for me not to make the suggested changes?' Again, follow-up e-mail dialogue was helpful in clarifying the feedback and helping students to understand its value and purpose. Orsmond et al. (2005) found that a majority of students preferred verbal feedback from lecturers as it enabled questioning and discussion. Experience in this study suggests that the provision of audio feedback followed by e-mail exchange can also work well as a mechanism to promote useful dialogue between students and lecturers about assessment. Importantly, this is an informed dialogue as the students have already been engaged with the task and begun to develop their understanding of the requirements. We would argue that this elevates the level of the discourse with the tutor and the relevance of the feedback to the students. We will return to this important issue later in relation to the student perceptions of the feedback and the impact of the feedback on attainment.

The students reported listening to the feedback on average three times (a minimum of twice and maximum of five or more). Overall, the students who chose to submit drafts seemed to both use and value the audio feedback. It is, however, unclear if these students 
Table 3 Student perceptions of audio feedback (survey results) following provision of formative feedback via audio files.

\begin{tabular}{|c|c|c|c|c|c|c|}
\hline Question & $\begin{array}{l}\text { Strongly } \\
\text { Agree }\end{array}$ & Agree & Neutral & Disagree & $\begin{array}{l}\text { Strongly } \\
\text { Disagree }\end{array}$ & Chart \\
\hline Q1. I felt that the audio feedback was helpful & 7 & 10 & 0 & 0 & 0 & \\
\hline $\begin{array}{l}\text { Q2. I felt that audio feedback was more } \\
\text { engaging than written feedback }\end{array}$ & 0 & 12 & 4 & 1 & 0 & \\
\hline $\begin{array}{l}\text { Q3. I felt that audio feedback was more } \\
\text { detailed than written feedback }\end{array}$ & 1 & 11 & 3 & 2 & 0 & \\
\hline $\begin{array}{l}\text { Q4. I felt that it was easier to act on audio } \\
\text { feedback than written feedback }\end{array}$ & 2 & 6 & 5 & 4 & 0 & \\
\hline \multirow[t]{2}{*}{$\begin{array}{l}\text { Q5. I feel that audio feedback is better than } \\
\text { written feedback }\end{array}$} & 1 & 7 & 5 & 4 & 0 & \\
\hline & Yes & No & Maybe & Both & No answer & \\
\hline $\begin{array}{l}\text { Q6. Would you like to receive this type of } \\
\text { feedback from all lecturers? }\end{array}$ & 9 & 2 & 2 & 2 & 2 & \\
\hline
\end{tabular}

are preconditioned, perhaps by their previous experience of assessment, to value feedback in comparison to those students who chose not to submit a draft. In fact, this work tells us very little about why students chose not to submit drafts, but from a lecturers perspective it was disappointing that nearly one third of the cohort did not demonstrate the autonomous independent learning characteristics we would like them to. Hamshire et al. (2009) consider autonomous independent learning to be a function of both students' personal autonomy (learning skill set) and their level of intrinsic motivation (want or need to learn). They perceived a strong link between autonomy and motivation, but emphasise that the two are not synonymous, e.g. a highly autonomous student may not be motivated by tasks considered not relevant directly to their studies while a highly motivated student may simply not have the experience or learning skill set to engage effectively in independent learning. The reasons behind non-submission in the current study need to be explored in more detail in future work, but an initial response may be to invest more effort in explaining the benefits and highlighting opportunity to improve marks, enhancing the want or need to learn, to the students when the assignment is initially set. However, this does not address those students with a limited learning skills set and this may be an issue that needs to be dealt with at a programme rather than unit/module level.

\section{The characteristics of audio feedback produced by the lecturer}

Audio feedback recordings were significantly longer for submissions classified as more complete (Table 2). Not surprisingly, the lecturer was able to make more comments, in more detail, where more complete work was submitted. For drafts classed as outlines, the feedback tended to focus on reiteration of the assignment task and suggestions about appropriate/additional evidence that might be included (Table 2). It was difficult for the 
lecturer to make positive comments on the work included in outline drafts, due to the low level of completeness, and less emphasis was drawn to grammar, spelling and referencing errors.

For drafts classified as being complete or works in progress, feedback included a higher proportion of positive, encouraging comments and a greater emphasis was placed on grammar, spelling and referencing errors. There is also some suggestion that for the most complete submissions more feedback was provided in relation to the structure of the work and slightly less to the content aspects.

Overall, the more complete the draft submission the more that the feedback produced by the lecturer seemed to focus on issues which may be regarded as fine tuning of the work. Although the lecturer's perception, during the marking of final submissions, was that almost all of the students had taken on board the majority of the feedback provided, it was not possible to retain copies of the student's final submissions and it has not been possible to compare them with draft submissions. This would have enabled a more direct assessment of the impact of the feedback on the students work submitted at different levels of completeness and is something that we are encouraged to do in future investigations. For example, it would be useful to determine if students benefit and respond more to feedback on drafts at the work in progress stage (when students still feel they have work to do) than feedback on more complete works (where students may be more reluctant to make significant changes as they perceive the work is finished).

Producing the audio feedback was perceived as being an efficient process by the lecturer. On average it took about 13 minutes in total to produce the individual audio feedback recordings. This breaks down as follows:

- A mean of eight minutes to print, read and mark the assignment (large variation here, between one and 21 minutes, depending upon the completeness and quality of the draft). There may be further efficiencies gained by undertaking the main marking process onscreen (see Cullen 2011).

- An average of three minutes to record the feedback.

- Approximately two minutes to copy, check, rename and send the file (this was reduced to one minute when done in a batch).

An assessment of the content of audio feedback found that three minutes of audio feedback was around 450-500 words of text if written down.

\section{Student perceptions of formative audio feedback}

All of the students who responded to the survey agreed or strongly agreed that the formative audio feedback had been helpful to them (Table 3, Q1). This was also evident from the Wordle diagram constructed in response to the survey question 'Please write down between two and four words to describe your experience of audio feedback' (Figure 2) where 'Helpful' was the dominant response. It is interesting to note that one student who regarded the feedback as helpful also included the word 'annoying' in their response. This may well reflect difficulties for some students in mapping comments in their audio feedback to specific sections of their work. For example, in some cases the audio feedback was quite detailed in nature and one student noted (as a confusion) that: 'I had to write down the things I needed to change... so had to keep stopping and starting the audio file' with another commenting 'when advising on paragraphs [it] was confusing as to which it was referred to'. Furthermore, when asked to make a text response about whether they would like to receive this feedback from all lecturers (summarised in Table 3, Q6) although the respondents were broadly positive, several attached the caveat that they would like both audio and written feedback, for example: 


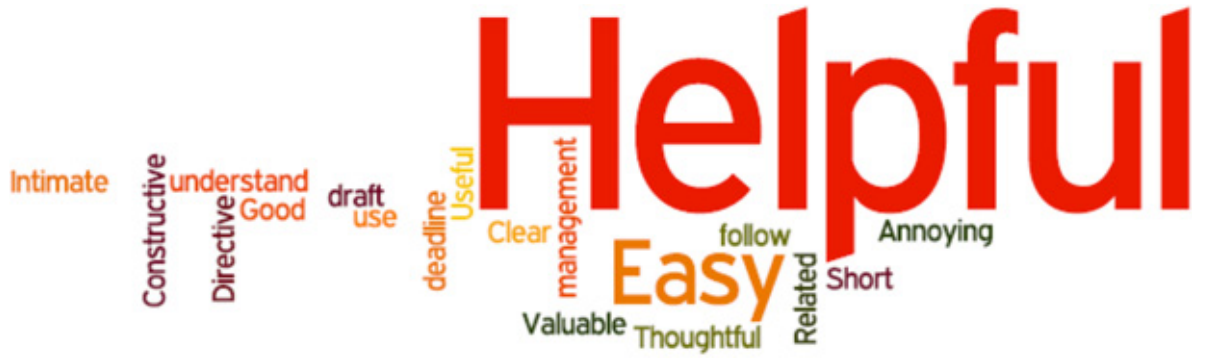

Figure 2 Wordle (http://www.wordle.net) diagram of responses to the question: 'Please write down between two and four words to describe your experience of audio feedback.'

\begin{abstract}
'Yes would probably be better with feedback in paper form too i.e. which paragraph etc.'
\end{abstract}

'If you receive written feedback too.'

'Yes, it is helpful but I find written feedback easier to act on.'

It is not completely clear from the comments earlier if students would like written versions of the audio feedback or complementary text on their work that would help them to orientate themselves to specific sections/paragraphs, however, it is clear that for some students there is a difficulty in mapping the audio feedback to their work and consequently working out an appropriate course of action. To some extent this is also reflected in the student responses that were more mixed in relation to audio feedback being easier to act upon (Table 3, Q4) and in general terms better (Table 3, 05) than written feedback as in both cases more students were neutral or disagreed about the benefit of audio feedback.

These findings may relate to the lecturer's experience and technique in producing the audio feedback as, on reflection, in some places it was obviously not clear enough to which paragraph/section of the work comments referred to. One way of addressing this issue would be to require students to add page and line numbers when completing their assignments and using these to refer more specifically to the work. Cullen (2011) has addressed this by marking on-screen and briefly annotating student scripts (submitted using Microsoft Word) using the 'comments' and 'track changes' tools and using these to orientate students with more detailed audio feedback provided. Students in Cullen's (2011) study reported that these annotations were an essential element of both audio and video screen capture feedback provision. Marking and annotating scripts with text comments on-screen in this way may well provide the mapping that some of the students in this study clearly desire and mitigate the requests to provide written versions of the text based feedback. This is an area for future work and development in practice.

In other comparisons with more familiar written feedback, responses were generally positive towards audio feedback with the majority considering it to be more engaging (Table 3, Q2) and more detailed (Table 3, Q3). This is in line with France \& Wheeler (2007) and Merry \& Orsmond $(2007,2008)$ who noted that audio feedback can be more hard-hitting due to factors including its personalised nature, the tone of voice providing a clearer context to some comments and that students treat it less superficially as it is less difficult to ignore parts of it and it has more depth because possible strategies for improvement are suggested.

More than half of the respondents felt that audio feedback should be provided by all lecturers and a further quarter were positive but added caveats relating to provision of accompanying written feedback and/or provision for some but not all assignments. The text responses suggest that, for some of these students, the opportunity to respond to the 
feedback on the draft and improving marks is as at least as important as the audio format of the feedback, for example,

'Yes, I thought it was great. All assignments should have a draft deadline with feedback'

'Getting feedback on a draft is very helpful and the audio feedback was really helpful for relating to the work, so it would be good to receive from all lecturers'

'Yes would be good to get this on all assignments would help improve my mark'

This is an important point highlighting the two interacting elements in this study (the timeliness of the feedback, i.e. provided on the task in hand to enable students to respond and improve their marks, and the format of the feedback, i.e. audio recordings). Bloxham \& Campbell (2010) argue that giving students control of the dialogue between them and their lecturers enables them to both get specific help on matters of concern and engages them with their feedback in the context of the goals and standards of their subject discipline. The provision of feedback on the draft, in the current study, to some extent formalises an opportunity for dialogue to take place between the student and the lecturer about the assignment being undertaken. Again, we would highlight that this is an informed dialogue, underpinned by the students having engaged in the assessment task. Some of the students clearly valued this and took the opportunity to engage in dialogue via follow-up e-mail exchanges and at the end of lectures. It may be an idea to timetable face-to-face sessions to facilitate this even more. Many studies have reported on the personal and engaging nature of audio feedback (e.g. Cooper 2008, Ice et al. 2008, Merry \& Orsmond 2008) and results discussed earlier add further support to this. What is not clear from this study is the relative importance of, or synergy between, these two elements in enhancing engagement with and the impact of the feedback although we strongly suspect that the timing of the feedback is more important.

\section{The impact of formative audio feedback on final submissions and attainment}

The mean final mark awarded for the assignment was significantly higher $(t=2.54 p=0.016)$ for students who submitted a draft and received audio feedback (60.8\%) than for those who chose not to submit a draft and consequently received no feedback (52.6\%). This represents almost a full degree classification difference with some marks for students that did not submit a draft being particularly poor (often a low third class mark; see Figure 3).

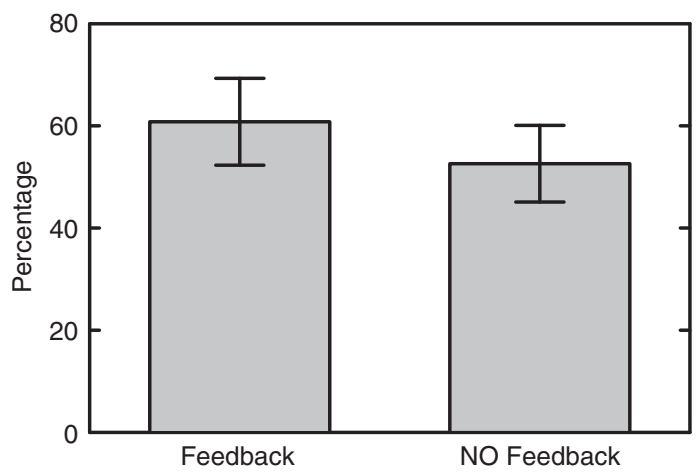

Figure 3 Mean ( \pm standard error) marks of students who did and did not submit draft essays and received feedback via audio files. Means were significantly different $(t=2.54, p=0.016, n=39)$. Note: One student's mark was not used in this analysis due to an issue of plagiarism being identified. 
It would be incorrect to attribute the differences in attainment simply to the impact of receiving formative audio feedback. It may well be that more able students simply adopt strategies to organise themselves better in order to submit the draft of their work on time. This is supported in that drafts classified as 'complete' tended to be submitted in advance of the deadline and ultimately lead to higher marks in the assignment (Table 2) and, as mentioned previously, comments citing poor time management as reasons for non-submission of drafts.

Interestingly, the mean marks for students who chose not to submit a draft were similar to those attained by students who submitted drafts that we classed as 'outlines' suggesting that those students who submit 'outline' drafts do not benefit to any great extent from the feedback they receive. This could be related to the student's ability to use the feedback provided on outline drafts, which tended to be shorter and focused on reiteration of the assessment task and suggestions for appropriate evidence (Table 2). If the students have not engaged with the assignment sufficiently to demonstrate their understanding of it, it is not surprising that they find it difficult to make use of any feedback that they receive. This is not the fault of the lecturer, it simply reflects there being less to feedback on for outline drafts and that the students have not fully engaged with and/or understood the requirements of the assignment.

When we look more closely at the attainment of students who submitted drafts, we can see that students who submitted drafts classified as 'complete' or 'work in progress' were awarded significantly higher final marks for the assignment than those students who submitted 'outline' drafts (Table 2). The general trend was for higher final marks to be awarded for work that was more complete at the draft stage. Furthermore, final marks for the assignment related very closely to the overall mark attained in the second year (Table 2), i.e. those students who were generally higher attaining were more likely to submit more complete drafts and perform better on the assignment. This adds further weight to the argument that generally more able students are more likely to submit drafts that are more complete.

Overall, it seems fair to suggest that students who submit more complete drafts have spent more time on the task and, having fine tuned their work, have been more engaged with the detailed requirements of the assignment. Having a better understanding of the assignment may enable these students to recognise the relevance of the feedback that they receive on their work especially as lecturers are able to provide feedback at finer resolution for more complete drafts. Put differently, we might suggest that better students (implying more autonomous, independent learners) are more likely to engage with and take advantage of purely formative assessment opportunities and this may lead us to the question, are we simply helping better students to perform even better?

\section{Conclusion}

This was a small-scale action research project. We recognise that the numbers of students was small but we feel that our findings illustrate some interesting issues in relation to the production of feedback and the subsequent effectiveness of feedback provided by the lecturer on formative assessment activities.

Nearly half of the cohort either did not take up the opportunity to submit a draft and receive feedback on their work or submitted work at such an early stage of development so as to give the lecturer very limited scope to provide meaningful feedback. More complete drafts were generally submitted in advance of the submission date and led to higher marks for the assignment but this cannot be directly attributed to provision and use of formative audio feedback. Although there is evidence to suggest that the students use and value the 
feedback they receive, those who submit more complete drafts tend to achieve higher marks overall. This suggests that these students are generally more capable and this is reflected in their organisational abilities and willingness to engage with formative activities. There is also some evidence suggesting that poor time management and a lack of strategic awareness of the benefits of receiving feedback may characterise those students who do not submit drafts.

A key finding of this study is that the level of completeness of drafts impacts on the characteristics of the feedback that the lecturer can produce. Generally, for more complete drafts the feedback focused on issues of fine tuning such as grammar, spelling and referencing errors and a high proportion of positive encouraging comments. For less complete work the feedback tended to focus on reiteration of the task and suggestions for evidence to support the assignment. The impact of the feedback provided may also be related to the level of completeness of the draft submission. Submission of more complete works suggests that students have spent more time engaged with the task leading to better understanding of the requirements of the assignment and are therefore better able to respond to feedback. We are encouraged to explore this in future by retaining copies of draft submissions for direct comparison with final submissions to assess student interpretation and impact of feedback on final attainment. This would also enable us to explore students' readiness to re-work drafts at different levels of completeness.

The production of audio feedback was found, by the lecturer, to be easy and efficient in terms of their time investment. The students reported that the feedback was clear, engaging and helpful but it became apparent that the technique adopted could be refined in future to help students map feedback comments more specifically to their work. This could involve onscreen marking and annotation of electronic submissions instead of marking printed hard copies. Despite the positive reception of the audio feedback format, the provision of the feedback at a point when recipients can respond to it and engage in clarifying dialogue with the tutor before submitting the work for formal assessment may be of greater importance in terms of impact on attainment. There is a need in this respect to explore ways of ensuring that all students recognise the benefit of formative feedback, otherwise

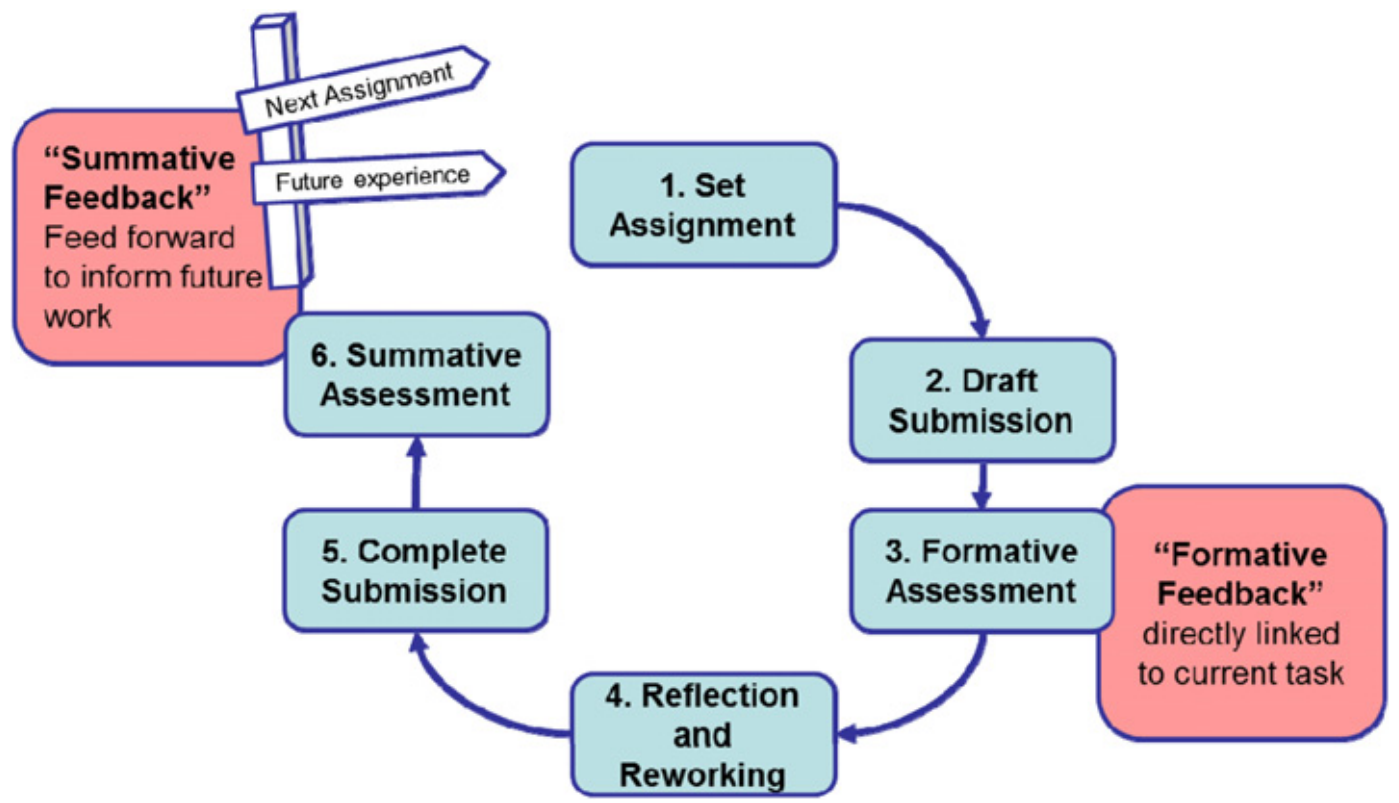

Figure 4 Targeting feedback provision effectively by providing formative feedback that is directly linked to the current assignment and ensuring that summative feedback 'feeds forward' to future assignments and experiences. 
there is a risk of simply helping more able students perform even better without engaging those students who would potentially benefit the most.

Finally, this paper is based on a belief that feedback can be targeted more effectively at assessment tasks. Black \& Wiliam (1998a) report that to some the roles of formative and summative assessment are so different that they should be kept apart, however, given the two are so closely entwined in current practice we concur with Black \& Wiliam (1998b) that this will be difficult to achieve. We advocate a model (Figure 4) that focuses more efforts on formative feedback directly linked to the assignment-in-hand (at a time when students are able to respond to it) and to be more selective in provision of summative feedback (targeted feed forward) that provides important signposting to where learning from the current work can be applied to future assignments and learning experiences.

\section{References}

Biggs, J.B. and Tang, C. (2007) Teaching for quality learning at university. Maidenhead, Open University Press/McGraw-Hill Education.

Black, P.J. and Wiliam, D. (1998a) Inside the black box: Raising standards through classroom assessment. Phi Delta Kappan 80, 139-148 available at http://weaeducation.typepad.co.uk/ files/blackbox-1.pdf.

Black, P.J. and Wiliam, D. (1998b) Assessment and classroom learning, assessment in education. Principles, Policy and Practice 5 (1), 7-74.

Bloxham, S. and Boyd, P. (2007) Developing effective assessment in higher education: a practical guide. Maidenhead, Open University Press.

Bloxham, S. and Campbell, L. (2010) Generating dialogue in assessment feedback: exploring the use of interactive cover sheets. Assessment and Evaluation in Higher Education 35, 291-300.

Carr, W. and Kemmis, S. (1986) Becoming critical: education, knowledge and action research. Lewes, Falmer.

Cooper, S. (2008) Delivering student feedback in higher education: the role of podcasting. Journal of Music, Technology and Education 1, 153-165.

Cullen, W.R. (2011) A multi-technology formative assessment strategy, media-enhanced feedback case studies and methods. In Proceedings of the Media-enhanced Feedback Event, 2010 Sheffield (ed. A. Middleton), pp28-33 available at http://ppp.chester.ac.uk/images/ archive/4/43/20110329150219!Middleton-Media-enhanced_feedback_proceedings-final.pdf (accessed 21 November 2012).

Fielding, A.F., Dunleavy, P.J. and Langan, A.M. (2010) Effective use of the UK's National Student (Satisfaction) Survey (NSS) data in science and engineering subjects. Journal of Further and Higher Education 33, 347-368.

France, D. and Wheeler, A. (2007) Reflections on using podcasting for student feedback. Planet 18, 9-11.

Gibbs, G. and Simpson, C. (2004) Conditions under which assessment supports learning. Learning and Teaching in Higher Education 1, 3-31.

Glover, C. and Brown, E. (2006) Written feedback for students: too much, too detailed or too incomprehensible to be effective? Bioscience Education 7 available at http://www. bioscience.heacademy.ac.uk/journal/vol7/beej-7-3.pdf (accessed 21st November 2012). 
Hamshire, C.H., Cullen, W.R. and Wibberley, C. (2009) Autonomy, motivation and IT skills: impacts on student engagement with eLearning in level 1 physiotherapy students. PRIME 3 (2), 37-48.

Holmes, K. and Papageorgiou, G. (2009) Good, bad and insufficient: students' expectations, perceptions and uses of feedback. Journal of Hospitality, Leisure, Sport and Tourism Education 8, 85-96.

Ice, P., Swan, K., Kupczynski, L. and Richardson, J. (2008) The impact of asynchronous audio feedback on teaching and social presence: a survey of current research. In Proceedings of World Conference on Educational Multimedia, Hypermedia and Telecommunications 2008 Chesapeake, pp5646-5649.

Jollands, M., McCallum, N. and Bondy, J. (2009) If students want feedback why don't they collect their assignments? In Proceedings of 20th Australasian Association for Engineering Education Conference, 2009, University of Adelaide, pp735-740.

Lipsett, A. (2007) Students' biggest concern is feedback. Available at http://www.guardian. co.uk/education/2007/sep/12/highereducation.uk2 (accessed 21 November 2012).

McClean, S. (2008) Making small talk - audio MP3 files made more portable. Bioscience Education 12 (1). DOI: 10.3108/beej.12.I1.

McCullagh, C. (2011) Talking about writing: exploring the use of audio feedback in EAP writing classes, Media-Enhanced Feedback case studies and methods. In Proceedings of the Media-Enhanced Feedback event, 2010, Sheffield, pp28-33 available at http://ppp.chester.ac. uk/images/archive/4/43/20110329150219!Middleton-Media-enhanced_feedback_proceedingsfinal.pdf (accessed 21 November 2012).

Merry, S. and Orsmond, P. (2007) Feedback via MP3 audio files. Centre for Bioscience Bulletin 22, 5 .

Merry, S. and Orsmond, P. (2008) Students' attitudes to and usage of academic feedback provided via audio files. Bioscience Education 11 (3). DOI: 10.3108/beej.11.3 (accessed 21 November 2012).

Middleton, A. (Ed.) (2011) Media-enhanced feedback case studies and methods. In Proceedings of the Media-enhanced Feedback Event, 2010, Sheffield, available at http://ppp. chester.ac.uk/images/archive/4/43/20110329150219!Middleton-Media-enhanced_feedback_ proceedings-final.pdf (accessed 21 November 2012).

Orsmond, P. and Merry, S. (2011) Feedback alignment: effective and ineffective links between tutors' and students' understanding of coursework feedback. Assessment and Evaluation in Higher Education 36, 125-136.

Orsmond, P., Merry, S. and Reiling, K. (2005) Biology students' utilization of tutors' formative feedback: a qualitative interview study, Assessment and Evaluation in Higher Education 30, 369-386.

Race, P. (2010) Making learning happen: a guide for post-compulsory education 2nd edition. London, Sage Publications Ltd.

Rotherham, B. (2007) Using an MP3 recorder to give feedback on student assignments. Educational Developments 8 (2), 7-10. 